\title{
GCU
}

Glasgow Caledonian

University

University for the Common Good

\section{A small-scale experimental investigation on the benefits of a hybrid pile/footing system on sand}

\author{
Maadheedi, M.A.; Hytiris, N.; Mickovski, S.B.
}

Published in:

DFI Journal

DOI:

10.37308/DFIJnl.20200929.225

Publication date:

2021

Document Version

Author accepted manuscript

Link to publication in ResearchOnline

Citation for published version (Harvard):

Maadheedi, MA, Hytiris, N \& Mickovski, SB 2021, 'A small-scale experimental investigation on the benefits of a hybrid pile/footing system on sand', DFI Journal, vol. 15, no. 2. https://doi.org/10.37308/DFIJnl.20200929.225

\section{General rights}

Copyright and moral rights for the publications made accessible in the public portal are retained by the authors and/or other copyright owners and it is a condition of accessing publications that users recognise and abide by the legal requirements associated with these rights.

Take down policy

If you believe that this document breaches copyright please view our takedown policy at https://edshare.gcu.ac.uk/id/eprint/5179 for details of how to contact us. 


\title{
A small-scale experimental investigation on the benefits of a hybrid pile/footing system on sand
}

\author{
Mohammed Al Maadheedi ${ }^{1 *}$, Nick Hytiris ${ }^{2 *}$ and Slobodan B. Mickovski ${ }^{3 *}$
}

\begin{abstract}
This paper explores the capacity effects of a square steel plate welded at the ground surface on a driven open-ended steel pile (i.e. the plate would touch the ground surface after the pile achieves the required penetration). A series of strain-controlled, 1-g small-scale laboratory tests were undertaken on piles with and without a square steel plate attached. The piles were driven in dry, loosely packed, uniform sand. Two plates were used, one with a breadth equal to two times the diameter of the pile (2D) and the other with a breadth equal to three times the diameter of the piles (3D). A $20 \%$ increase in capacity was recorded for the $2 \mathrm{D}$ plate, and a $110 \%$ increase in capacity was recorded for the 3D plate when compared to the pile without an attached steel plate. The back-analysis of the results allowed the derivation of a new expression to calculate the capacity of bearing plates and plot its load-settlement profile, which accounted for the effects of sands compaction and dilation. By extrapolating the findings of these tests to a hypothetical scenario, a model design problem was described where the length of a pile can be reduced by $20 \%$ to $60 \%$ (depending on the load) by using a plate attached to the pile. The results of this study can help designers to minimise penetration depth; thus, achieving a more economical and sustainable design.
\end{abstract}

\section{Keywords: Steel Piles, Pipe piles, Deep Foundations, Ground Improvement, Hybrid pile/footing.}

\section{Introduction}

Piled foundations are conventionally used to either overcome weak and compressible soil conditions or to bear relatively high loads. This paper explores a more sustainable and economical pile design. The proposed pile is shown in Fig. 1, where the bearing plate helps to compact the surface soil and acts as a surface footing. This increases the overall capacity of the pile, which in turn reduces the depth of the pile and/or provide an additional factor of safety against either excessive settlement or failure. It should be noted that this research covers single jacked piles (i.e.

\footnotetext{
${ }^{1}$ Graduate Geotechnical Engineer at Wood Thilsted, B.Sc, M.Sc, E: mam@woodthilsted.com

2 Professor in Civil Engineering/Geotechnics and Environmental Geotechnology, BSc.,

MSc.,PhD,.C.Eng.,FHEA.,Mem.Tech.Chamb.Greece, (former FGS.,MCIMM.,MIHT.), E: n.hytiris@gcu.ac.uk

${ }^{3}$ Professor in Civil Engineering \& Environmental Technology, PhD, CEng MICE, SFHEA, E:

slobodan.mickovski@gcu.ac.uk

* Glasgow Caledonian University, Glasgow, UK,
} 
piles not set in clusters) which are conventionally used as foundations for bridges, coastal platforms, and wind turbines (Kim and Andrawes, 2017). Admittedly, the driving method adopted in this experiment differ from conventional methods on site. However, this study is meant as a proof-of-concept to facilitate future studies in this field.

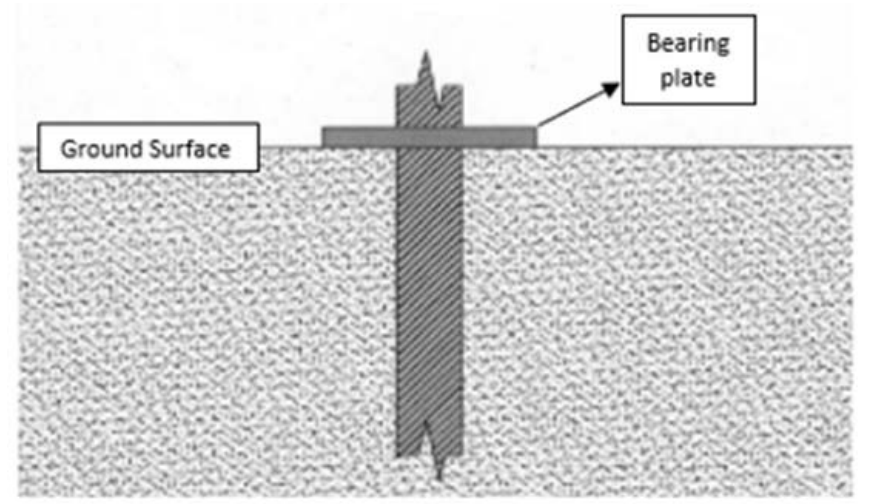

Fig. 1. Schematic diagram of the proposed pile

A series of 1-g displacement-control tests were conducted in Glasgow Caledonian University geotechnical laboratory, where hollow steel pipes were driven in dry loose sand. The testing programme consisted of three parts: the first involved driving a model pipe without attaching a plate. The second and third part involved welding square steel plates with breadths equals to two times (2D) and three times (3D) the diameter of the used pipe, respectively. Three trials were conducted for each part. The effect of attaching the bearing plate is discussed in the contexts of ground improvement and sand dilation.

\section{Methodology}

A wooden box was manufactured for the tests to take place in. The size was restricted to the maximum dimensions and lift allowed by the triaxial machine, as shown in Fig. 2 ( $0.344 \times 0.339 \times 0.41 \mathrm{~m}$ outer dimensions; $0.3 \times 0.305 \times 0.4 \mathrm{~m}$ inner dimensions). A hot-rolled steel pipe with $0.034 \mathrm{~m}$ outside diameter and $0.006 \mathrm{~m}$ wall thickness was cut into $0.3 \mathrm{~m}$ long pieces to model a pile. The 2D and 3D plates have breadths of $0.07 \mathrm{~m}$ and $0.1 \mathrm{~m}$, respectively. Both plates have a thickness of $0.006 \mathrm{~m}$ for them to act as rigid footings. Both plates are welded at a depth of $0.05 \mathrm{~m}$ from the pipe's head. The pipe will penetrate a total of $0.27 \mathrm{~m}$ into the sand. Considering the influence of the boundary, the model dimensions provide a minimum constant vertical offset of 4D and a minimum horizontal offset of 3D. Pressure bulb calculations following Ahlvin and Ulery (1962) and Fadum (1948) approaches (cited in Whitlow, 2001) show that the dimensions 
chosen are appropriate to avoid any significant boundary effect. It should be noted that these calculations are for stresses well below yield stress of soil, as the equations are derived based on elasticity theory. Therefore, these calculations are meant as indicative only. It should be noted that the soil/structure interaction between the sand the walls of the box has also been disregarded due to the comparative nature of the experiment.

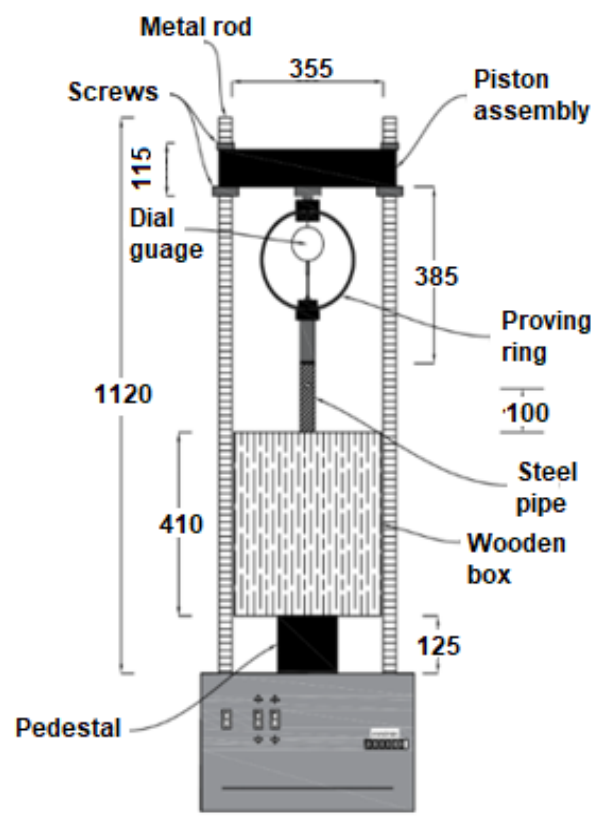

(A)

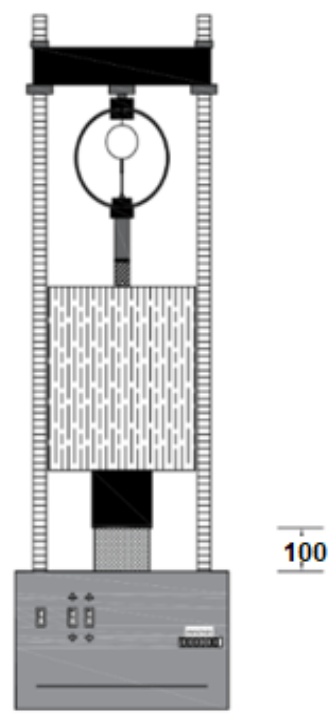

(B)

Fig. 2. Dimensions and elements within the triaxial machine, $(A)$ start of trial and (B) End of trial [dimensions are in $\mathrm{mm}$ ]

Leighton Buzzard sand was used as a model granular soil for the tests. In order to achieve a constant dry state, $60 \mathrm{~kg}$ of the sand was dried once and covered after every trial. Particle size distribution, minimum dry density $\left(\rho_{\mathrm{d}, \mathrm{min}}\right)$ and maximum dry density $\left(\rho_{\mathrm{d}, \mathrm{max}}\right)$ tests were conducted as per BS 1377:1990. The $\rho_{\mathrm{d} \text {,max }}$ test was modified as the electric vibrator was not available. Head (2006) provided an expression for calculating the compaction energy applied in each standard test, where a compaction effort of $11739 \mathrm{~kJ} / \mathrm{m}^{3}$ had to be applied to achieve $\rho_{\mathrm{d}, \max }$. This was achieved by using the $4.5 \mathrm{~kg}$ drop hammer to apply 197 blows per layer. The rest of the procedures were identical to those outlined in BS 1377:1990.

Table 1 shows the soil properties determined in this paper. The soil properties given in the table fall within the tests results of other researchers (Stroud, 1971 [cited in Bolton, 1986]; Been et al., 1991; Cavallaro et al., 2001; Penna et al., 2016 and Al-Aghbari and Mohamedzein, 2004). Same 
researchers report specific gravity $\left(G_{s}\right)$ ranging from 2.64 to 2.68, and $C_{u}$ values ranging from 1.39 to 2.13 .

Table 1. Leighton Buzzard sand properties obtained from lab tests

\begin{tabular}{ccccc}
\hline$\rho_{\mathrm{d}, \mathrm{min}, \mathrm{kg} / \mathrm{m}^{3}}$ & $\rho_{\mathrm{d}, \mathrm{max}}, \mathrm{kg} / \mathrm{m}^{3}$ & $\mathrm{~d}_{10}(\mathrm{~mm})$ & $\mathrm{d}_{50}(\mathrm{~mm})$ & Coefficient of uniformity, $\mathrm{C}_{\mathrm{u}}$ \\
\hline 1428 & 1818 & 0.08 & 0.2 & 2.75 \\
\hline
\end{tabular}

To explore the effect of the plate on loose sands, the relative density $\left(\mathrm{I}_{\mathrm{D}}\right)$ must be between 0.15 to 0.35 (Whitlow, 2001). A density of $1500 \mathrm{~kg} / \mathrm{m}^{3}$ was selected to achieve a constant $I_{D}$ of 0.22 . A $50 \mathrm{~mm}$ scale was drawn inside the box marking various layers, where each layer was filled with $6.86 \mathrm{~kg}$ of sand to control the density. Once the box is filled, the model pipe was manually pushed $0.17 \mathrm{~m}$ into the sand. The triaxial apparatus used in this experiment is modified where the cell is removed and the box is fitted on the pedestal, to allow strain-controlled tests. This allows a further penetration of $0.1 \mathrm{~m}$ to be applied at a rate of $5 \mathrm{~mm} / \mathrm{minute}$. The dial gauge was read every 15 seconds (or $1.25 \mathrm{~mm}$ penetration); thus, each trial lasted for approximately 20 minutes. Several control measures were put in place to ensure the consistency of the obtained results:

- Ensuring both verticality and no concentricity,

- Emptying and refilling the box after each trial, to control the density of the soil,

- Checking the mass of the sand before and after every trial,

- Periodically checking the moisture content of the stored sand to ensure a dry state,

- $\quad$ Pouring the sand gently over the box to avoid dynamic compaction.

\section{Results}

Figure 3 shows the results of the first experimental programme. The coefficient of variability of load resistance between T1, T2 and T3 varied between 3\% to 7\% at different depths, with an average of $4.4 \%$. This reflects an adequate control over the extraneous variables which might have affected the results. However, initial load resistance varies between trials as the pile was initially manually inserted but this variation appears to be minimal. The plug length after manual driving was equal to $100 \mathrm{~mm} \pm 5 \mathrm{~mm}$. It stayed constant after mechanical driving by the triaxial machine; this is consistent with Igoe et al. (2001) and Deeks et al. (2005) findings for jacked piles. 


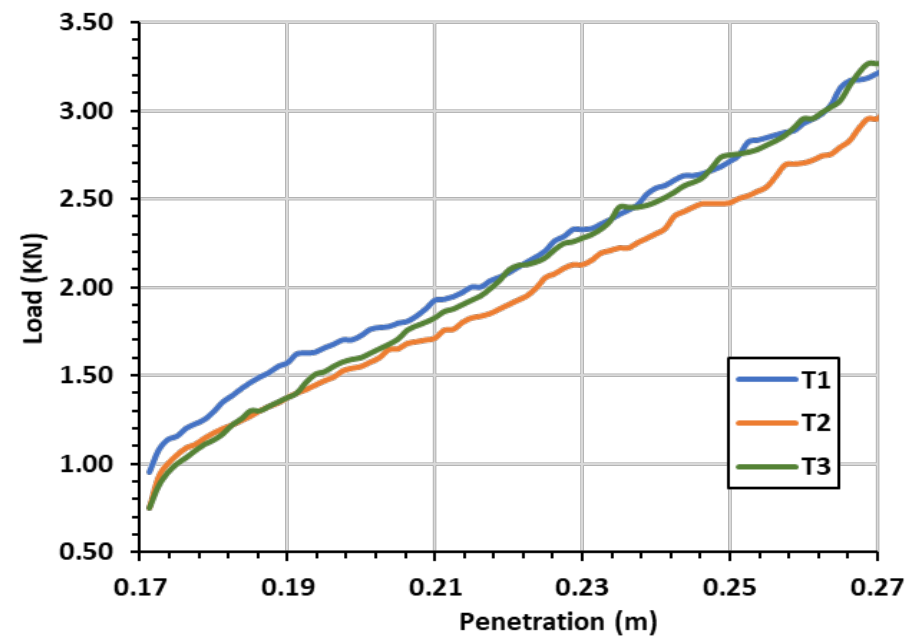

Fig. 3. Model piles' resistance profile

Figure 4 shows a comparison between the average load profile from Fig. 3 against the results with the $2 \mathrm{D}$ plate welded to the pipe. The ' $\mathrm{X}$ ' sign shows the depth at which the bearing plate is in contact with the soil. An average settlement of around 0.11B (where B $=2 \mathrm{D}$ ) took place for the plate to mobilise its ultimate capacity. A stiff response was noticed between the ' $\mathrm{X}$ ' marked and the circled portion of the graph, followed by noticeable softening. For the purpose of this study, we define the 'softening' as the post-peak softening that takes place once the dilation is suppressed and the volumetric strain stops increasing and becomes constant. Afterwards, the load-settlement continues as before, but with a steeper increase in the capacity.

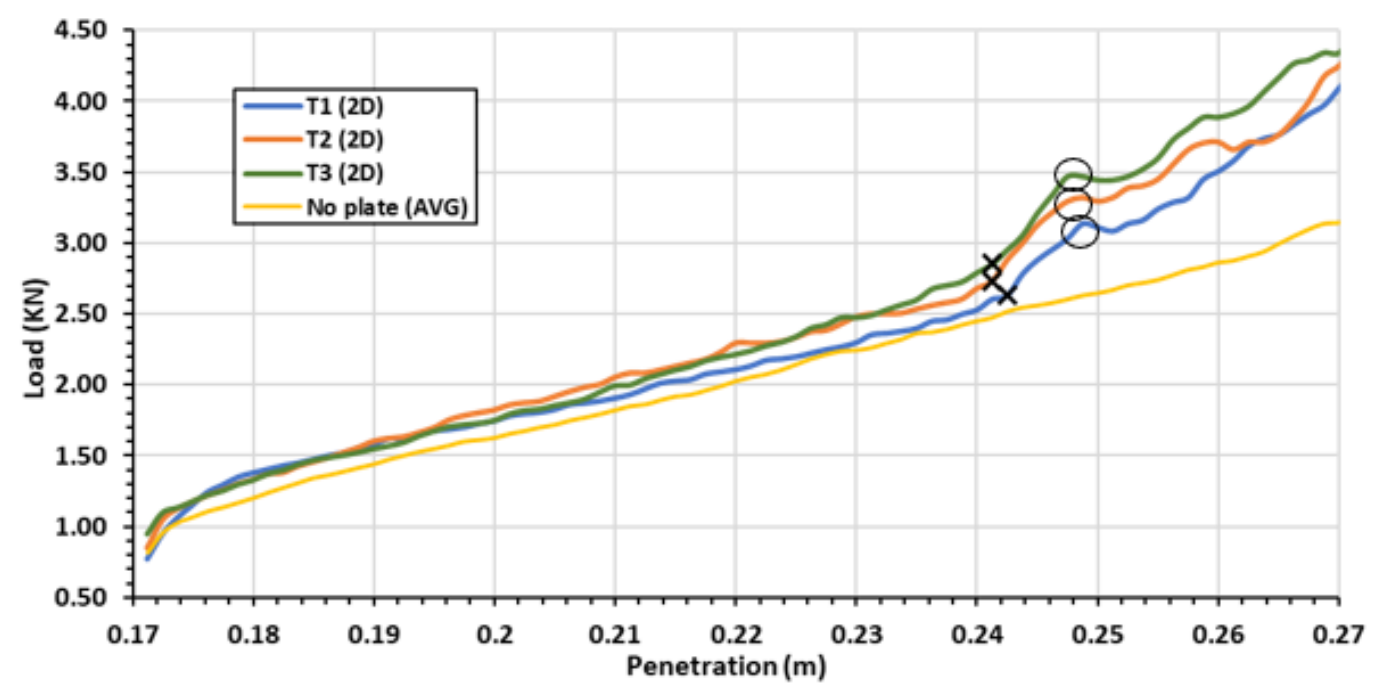

Fig. 4. Load profile for model pile with 2D plate welded

Figure 5 shows a comparison between the average load profiles shown in Figs. 3 and 4 against the load profiles obtained when the 3D plate was welded. As in Fig. 4; a very stiff response followed 
by softening is noticed. An average settlement of $0.13 \mathrm{~B}$ (where $\mathrm{B}=3 \mathrm{D}$ ) took place for the plate to mobilise its ultimate capacity.

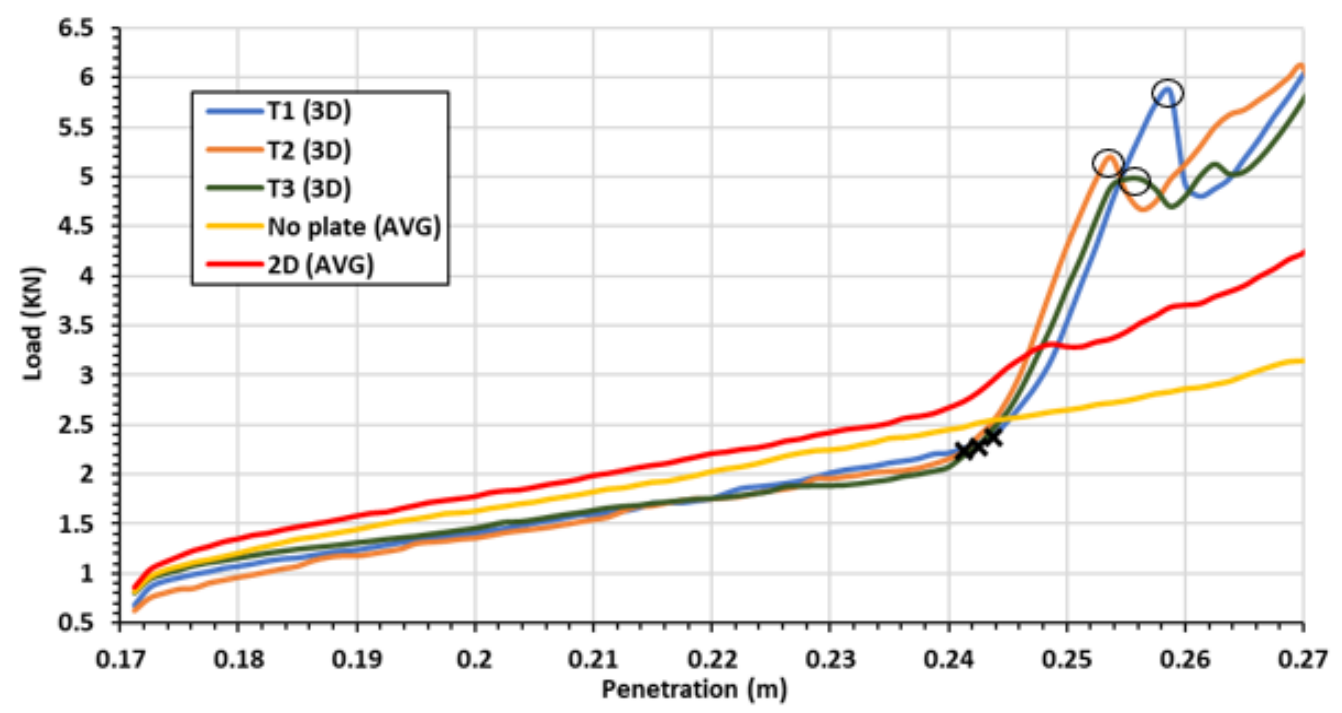

Fig. 5. Load profile for model pile with 3D plate welded

In both Figs. 4 and 5, the stiffest response is noticed when the bearing plate first get in contact with the ground level (the marked portion of the curve). Afterwards, softening like behaviour is noticed, which is more prominent for the $3 \mathrm{D}$ plate. The subsequent increase in capacity takes place at a lower rate (i.e. gentler slope) than the marked region. Thus, the focus of this paper is on this region and the reference to the bearing plate’s capacity hereafter would be for the marked region.

Interestingly, all the previous curves for the model pipes (and the portions of the pipe prior to the bearing plate reaches the ground) represent straight lines with an $\mathrm{R}^{2}>0.99$. This could be due to the relatively shallow penetration depth. This allows for a better quantification of the contribution of the bearing plate. By extending a predicted profile for the pipe after the plate touches the ground; the capacity of the bearing plate can be calculated more accurately. Figures 6a and 6b depict the capacities of the 2D and 3D bearing plates by utilising the previously outlined method. Average pre-softening capacities of $0.5 \mathrm{kN}$ and $2.67 \mathrm{kN}$ were recorded for the $2 \mathrm{D}$ and $3 \mathrm{D}$ bearing plates, respectively.

The results appear consistent between trials, with reasonably small variations that could be due to (1) the discontinuous and manual recording of loads/penetrations (especially for the location of peak loads), (2) changes in the distribution of particle sizes between trials, (3) zones of higher or 
lower densities in the box which also changes between trials and (4) the initial manual insertion of the piles for the different trials.

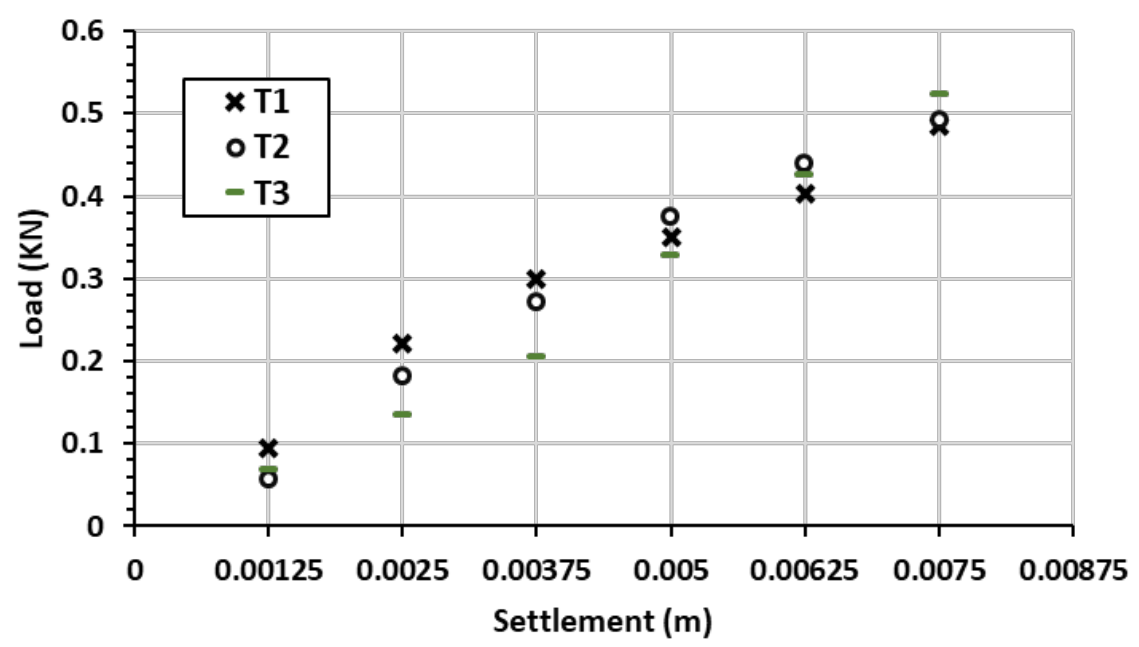

(a)

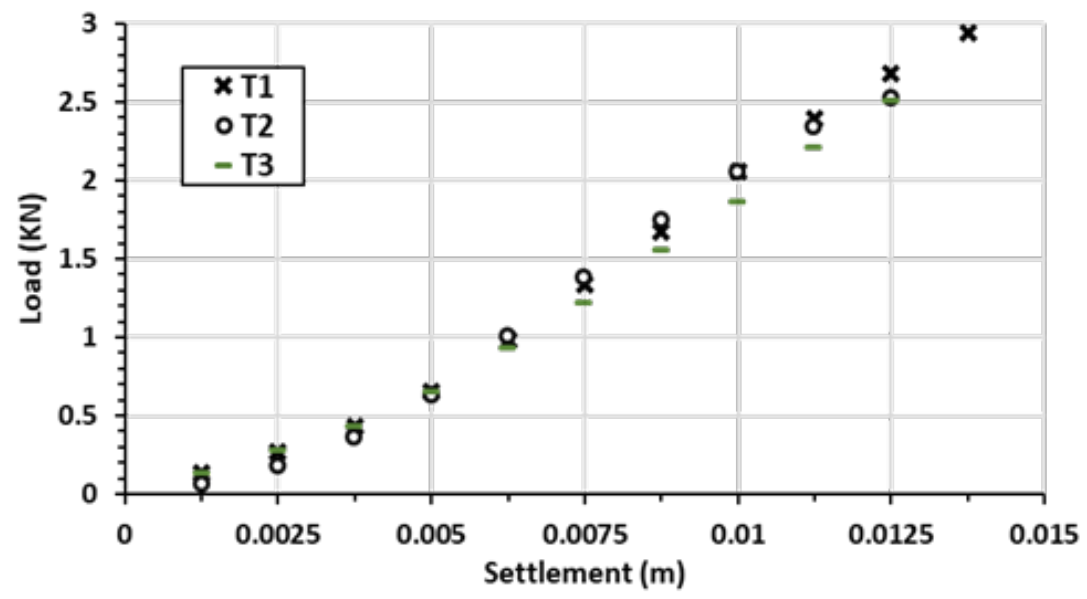

(b)

Fig. 6. Load-settlement profiles for (a) 2D bearing plate and (b) 3D bearing plate

\section{Calculations and discussion}

The bearing plate acted as an isolated footing in both cases. This was evident by the bulging and heaving of ground surface, which is consistent with a general shear failure exhibited by dense sands. The 2D bearing plate exhibited a lower degree of heaving when compared to the 3D plate. Also, a form of cracks appeared in the soil for the 3D plate, which most likely represent yield lines. Yield lines were absent for the trials that involved the 2D plate. This indicates that the 3D plate tends to compact the soil to a higher degree prior to failure when compared to the 2D plate. 
Additionally, the post-failure softening observed for the 3D plate (Fig 5) was much greater than the 2D plate (Fig 4); which indicates a denser sand.

Conventional bearing capacity equation grossly underestimate the capacities of both plates as the effects of dilations and compaction are not accounted for. The dilation of sands can be captured by Bolton (1986) approach. This consists of calculating an effective frictional angle ( $\phi$ ' eff) which primarily depends on the effective stress levels (p') applied to the soil and the relative density, as shown by equation [1]:

$\phi_{\text {eff }}^{\prime}=\phi_{c r i t}^{\prime}+m\left[\left\{I_{D}\left(Q-\ln p^{\prime}\right)\right\}-1\right]$

Where $\phi$ ' crit is the critical friction angle, $m$ is the mobilised peak strength ( $=3$ for triaxial conditions) and $\mathrm{Q}$ is the crushing strength of sand (=10 for silica-based sands). The values of $\mathrm{m}$ and $\mathrm{Q}$ are taken as recommended by Bolton (1986). This would indicate that the $\mathrm{N}_{\gamma}$ (or $\phi^{\prime}$ eff) of the 3D plate would be smaller than that of the 2D plate due to the difference in stresses. In fact, other researchers have noted that smaller footings mobilise greater $\phi_{\text {eff }}$ (Golder, 1941; Zhu et al., 2001; Teh, 2007 and White et al., 2008). In contrast, the initial back-calculation of the experimental results showed $\mathrm{N}_{\gamma}$ values of 440 and 684 for the 2D and 3D plates, respectively. This leads to the conclusion that the relative densities differ between them; meaning that the 3D plate tends to compact the soil more than the 2D plate, resulting in a greater $\phi_{\text {eff }}$ (and hence $\mathrm{N}_{\gamma}$ ). The previously cited research investigated dense sands only, where minimal compaction would take place prior to failure.

To calculate the capacity of similar plates, three things need to be considered: (1) the change in density due to compression, (2) the dilation of the sand and (3) the effective stress p'. The first factor can be accounted for by using the following relationship for isotropic compression and swelling:

$e=e_{0}-\kappa \cdot \ln p^{\prime}$

Where $\mathrm{e}_{0}$ is the initial void ratio, $\mathrm{e}$ is the final void ratio and $\kappa$ is the slope of the SwellingRecompression Line (SRL). At some circumstances using the slope of the Normal Compression Line (NCL) would be more appropriate as crushing of particles may take place (either very high stresses or sands with low crushing strength). Some researchers employed empiricism to determine p' by correlating it with the bearing resistance (q). Teh (2007) and White et al. (2008) 
recommended the following correlation based on the back-analysis of centrifuge tests on conical and circular footings on sand:

$p^{\prime}=0.15 q$

Circular footings are similar to square footings as both are under axisymmetric conditions. Thus; this relationship can also be applied to square footings. Equation [2] can be substituted into the equation of relative density to calculate the new relative density gained upon loading. The previous equation along with equation [3] can be substituted into equation [1] to calculate $\phi$ ' eff with respect to three previously mentioned factors:

$\phi_{\text {eff }}^{\prime}=\phi_{\text {crit }}^{\prime}+m\left[\left\{\frac{e_{\max }-\left(e_{0}-\kappa \cdot \ln 0.15 q\right)}{e_{\max }-e_{\min }}(Q-\ln 0.15 q)\right\}-1\right]$

Teh (2007) and White et al. (2008) suggested incorporating dilatancy equation into the bearing capacity equation. A similar approach is adopted here where equation [4] is incorporated in the bearing capacity equation with the $\mathrm{N}_{\gamma}$ proposed by Hansen (1961), the $\mathrm{N}_{\mathrm{q}}$ proposed by Reissner (1924) and the shape factor s $s_{\gamma}$ proposed by Vesic (1970), all cited in Whitlow (2001):

$q=0.5 \cdot \gamma \cdot B^{\prime} \cdot N_{\gamma} \cdot s_{\gamma}$

$=0.5 \cdot \gamma \cdot B^{\prime} \cdot 1.8\left(N_{q}-1\right) \tan \phi_{e f f}^{\prime} \cdot 0.6$

$=0.54 \cdot \gamma \cdot B^{\prime} \cdot\left(e^{\pi \tan \phi^{\prime}}{ }_{e f f} \cdot \tan ^{2}\left\{45+0.5 \phi^{\prime}{ }_{e f f}\right\}-1\right) \cdot \tan \phi^{\prime}{ }_{e f f}$

Where $\gamma$ is the unit weight of the soil and B' is the effective breadth of the plate ([area of pile area of plate $]^{1 / 2}$ ). The calculation of the bearing capacity can be done iteratively between equations [4] and [5]. This can be swiftly solved in MS Excel by using the built-in iterative solver. If the plate is to be buried at a shallow depth and then refilled with soil, an $\mathrm{N}_{\mathrm{q}}$ term would be added to equation [5] and the iterative process would go as usual. However, this effect is yet to be studied experimentally.

As far as the experimental results are concerned, the availability of the values of q for both plates allows the calculation of $\phi$ ' 'ff from equation [5]. The only unknowns would be $\phi$ ' crit and $\kappa$. Stroud (1971; cited in Bolton, 1986) gave a $\phi^{\prime}$ 'rrit value of Leighton Buzzard sand of $35^{\circ}$. As density changes with load, ID was back-calculated and a new $\gamma$ value would be inputted in equation [5]; until the back-calculated $\gamma$ converges with the inputted value. Table 2 shows the results of back- 
analysing the experimental data. A unique $\kappa$ value of 0.058 gave rise to an average $\phi^{\prime}$ crit of $35^{\circ}$ for both plates. Also, as noticed during laboratory procedures, the $3 \mathrm{D}$ plate compacts the soil to a higher degree which is reflected in an $I_{D}$ value greater than that of $2 \mathrm{D}$ plate. The $\phi$ ' eff for the 3D plate agrees well with the experimental results of Al-Aghbari and Mohamedzein (2004) for dense Leighton Buzzard sand.

Table 2. Results of the conducted back-analysis of the experimental data

\begin{tabular}{lcccccc}
\hline & $\mathrm{q}(\mathrm{kPa})$ & $\mathrm{N}_{\gamma}$ & $\begin{array}{c}\phi^{\prime}{ }_{\text {eff }} \\
\text { (degrees) }\end{array}$ & $\kappa$ & $\begin{array}{c}\phi^{\prime}{ }_{\text {crit }} \\
\text { (degrees) }\end{array}$ & $\mathrm{I}_{\mathrm{D}}$ \\
\hline 2D plate: & 125 & 399.6 & 45.26 & & 34.5 & 0.65 \\
3D plate: & 293.4 & 604.3 & 46.93 & & 35.5 & 0.78 \\
\hline
\end{tabular}

The difference between $\phi$ ' crit values between the 2D and 3D plates can be due to the accumulation of errors in the experimental procedures, taking an average q value, calculating the capacity of the plates by extrapolating a best fit profile for the piles and differences between cited equations and real values. The effect of attaching a bearing plate on the development of skin friction was not considered in this paper. As the plate applies vertical load onto the soil, the horizontal load will also increase. Hence skin friction is also expected to increase. Additionally, compaction of sand can also increase the skin friction on the upper part of the pile. This could account for the higher $\phi$ ' crit back-calculated for the 3D plate, as the increase in skin friction might be greater when compared to the $2 \mathrm{D}$ plate.

The slope of the SRL is influenced by the initial state of the soil. Based on both experimental and numerical results, Sun et al. (2015) stated that the compressibility of sands increases with a decrease in $I_{D}$ and an increase in $C_{u}$. The Leighton Buzzard sand used in the tests have a higher $C_{u}$ than reported in other works. Additionally, the sand was prepared with an $I_{D}$ of 0.22 . This explains the relatively large back-calculated $\kappa$ value.

\section{Load/settlement profile}

The settlement required for the bearing plate to reach its capacity can also be calculated. This is done by employing Equation [6] for 1-D compression. This is an over-simplification of the problem at hand but appears to give reasonably consistent results for both plates. The backcalculated $\mathrm{I}_{\mathrm{D}}$ allows the calculation of the final relative density $\left(\mathrm{I}_{\mathrm{D}}\right)$ at failure. This, in turn, would allow calculating the final void ratio using simple physical relationships of soil. 
$\frac{\Delta e}{1+e_{o}}=\frac{\Delta h}{h_{o}}$

Where $\Delta \mathrm{e}$ is the difference between the initial void ratio and back-calculated voids ratio after loading (calculated from final $\mathrm{I}_{\mathrm{D}}$ ),$\Delta \mathrm{h}$ is the settlement required to reach the capacity of the plate (Fig. 6) and $h_{0}$ is the depth of soil over which compression would take place (Whitlow, 2001). Since both $\Delta \mathrm{e}$ and $\Delta \mathrm{h}$ are known, $\mathrm{h}_{\mathrm{o}}$ was back-calculated for both 2D and 3D plates. Interestingly, $\mathrm{h}_{0}$ equals 1.12B and $\mathrm{B}$ for the $2 \mathrm{D}$ and $3 \mathrm{D}$ plates, respectively. It should be noted that this approach is an over-simplification of the problem, as volumetric changes take place in a 3-dimensional manner. This approach allows a simplified calculation of the final settlement exhibited by the footing.

Alternatively, the simple 1-D compression model can be extended to plot the entire load settlement profile. The underlying model developed to capture the load-settlement profile assumes that as the load increases, the effective depth at which soil compression takes place $\left(\mathrm{h}_{0}\right)$ also increases.

The change in $h_{o}$ with settlement was back-calculated from the experimental results by first taking the increments of bearing capacity ( $\mathrm{q}_{\text {inc }}$ ) prior to the average failure stresses (q). Afterwards, $\Delta \mathrm{e}$ and the resulting $e_{o}$ were back-calculated from Equations [2] and [3] for each value of qinc. This allowed the calculation of $\Delta \mathrm{h} / \mathrm{h}_{0}$ from Equation [6]. But since the settlement $(\Delta \mathrm{h})$ is also known, it was also possible to calculate $h_{0}$ for each value of $q_{\text {inc }}$ and for each trial. This allowed the empirical derivation of Equation [7] linking the settlement of the footing and the development of failure stresses:

$h_{o}=\left(0.508 e^{0.7 \frac{q_{\text {inc }}}{q}}\right) B^{\prime}$

Figure 7 shows that the empirical equation (Equation [7], the dashed line) agrees reasonably well with the back-calculated values of $h_{0}$, with an $\mathrm{R}^{2} \approx 0.85$. The load-settlement profile of the $2 \mathrm{D}$ plate (Fig. 8a next) is not as consistent as the 3D profile. This accounts for some of the outlying points shown in figure 7 . When compared to the 3D plate, the 2D plate exhibits a lower increase of stress and a lower final settlement. Thus, the load settlement profile of the 2D plate is more sensitive to inaccuracies regarding the recording of dial gauge readings and the extrapolation of 
forces developed in the model pile. Additionally, due to the smaller size of the 2D plate; it is more sensitive to local variability in the prepared soil sample.

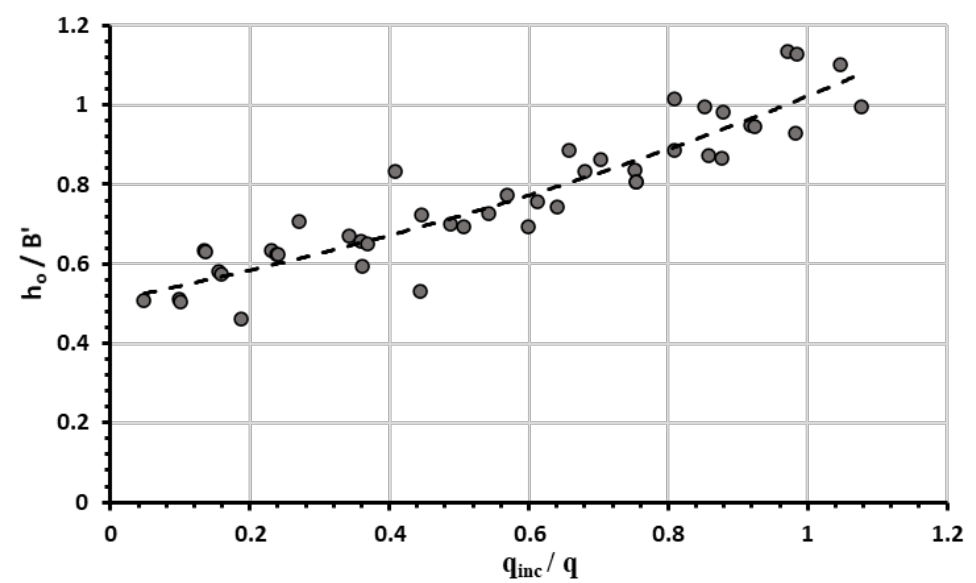

Fig. 7. Best fit and normalisation of the back-calculated $h_{0}$ values

Values of $\Delta e$ and $\mathrm{e}_{\mathrm{o}}$ values were first calculated for $\mathrm{q}_{\text {inc }}$ values with $10 \mathrm{kPa}$ increments. Afterwards, $\mathrm{h}_{\mathrm{o}}$ was calculated for each $\mathrm{q}_{\text {inc }}$ from Equation [7] which consequently allowed the calculation of settlement from Equation [6]. This procedure was used to replot the load settlement profiles, shown in Figs $8 \mathrm{a}$ and $8 \mathrm{~b}$ for the 2D and 3D plates response, respectively.

In both Figs 8a and 8b, the dotted lines represent the calculated settlement profile for the backcalculated $\phi$ ' crit (Table 2) while the dashed lines represent the load-settlement profile while taking a $\phi$ ' crit value of $35^{\circ}$. Similarly, the triangles represent the failure load (from the iterative method) and total settlement (from Equation [6] only) according to the back-calculated value of $\phi$ ' ${ }_{\text {crit. While }}$ the squares show the same but for a $\phi$ ' crit value of $35^{\circ}$. The proposed method agrees reasonably well with the recorded experimental readings.

The load-settlement results from the back-calculated $\phi$ ' crit shows better agreement than the value of $35^{\circ}$. The $\Delta \mathrm{e}$ does not change with different $\phi$ ' crit but the bearing capacity changes. Thus, $\mathrm{h}_{\mathrm{o}}$ value changes along with the settlement at each qinc. Due to the exponential nature of Equation [7], the closer $\mathrm{q}_{\text {inc }}$ to $\mathrm{q}$, the more the value of $\mathrm{q}$ has an influence on the load-settlement profile. This is reflected in Figs 8 as the dashed line diverge further from the experimental results towards the end. 


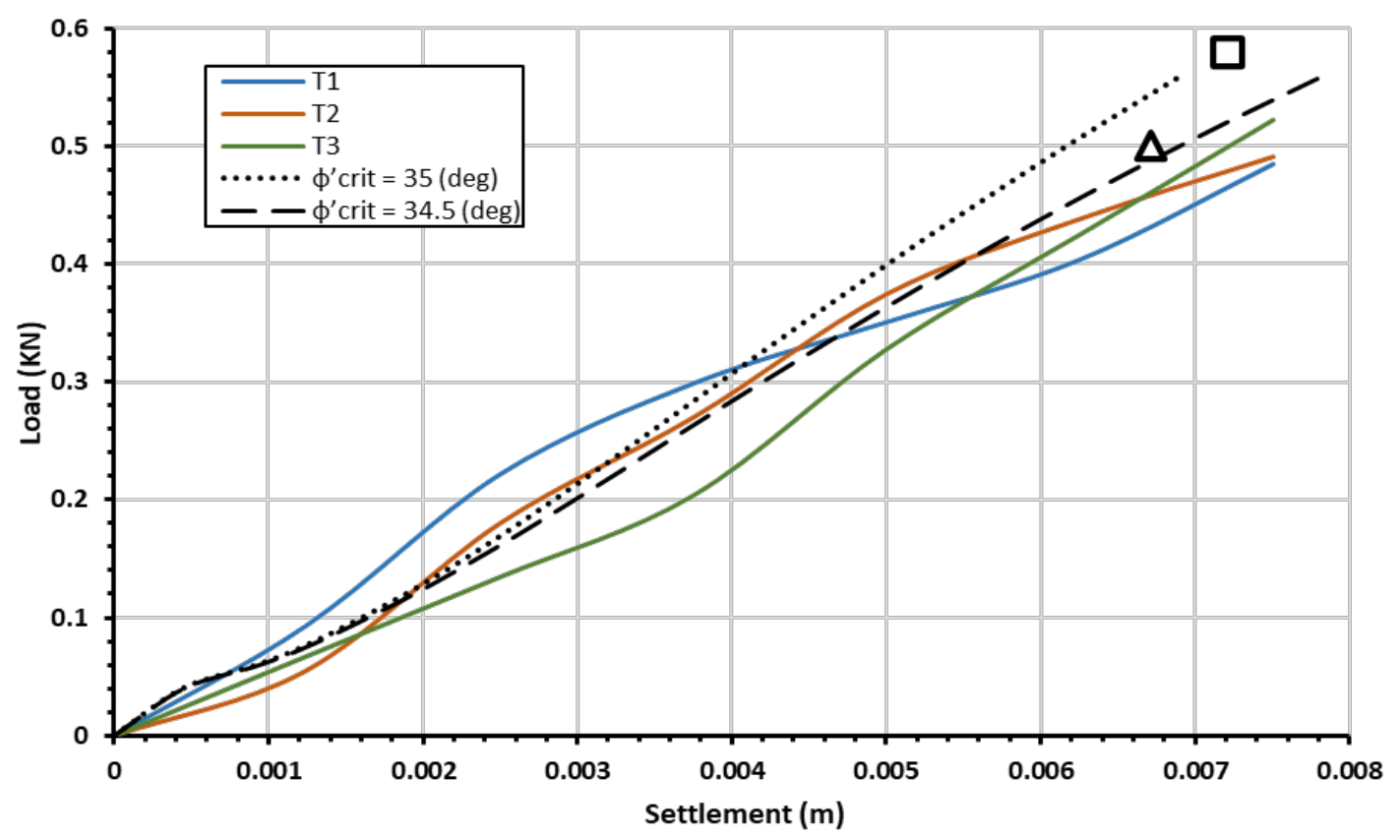

(a)

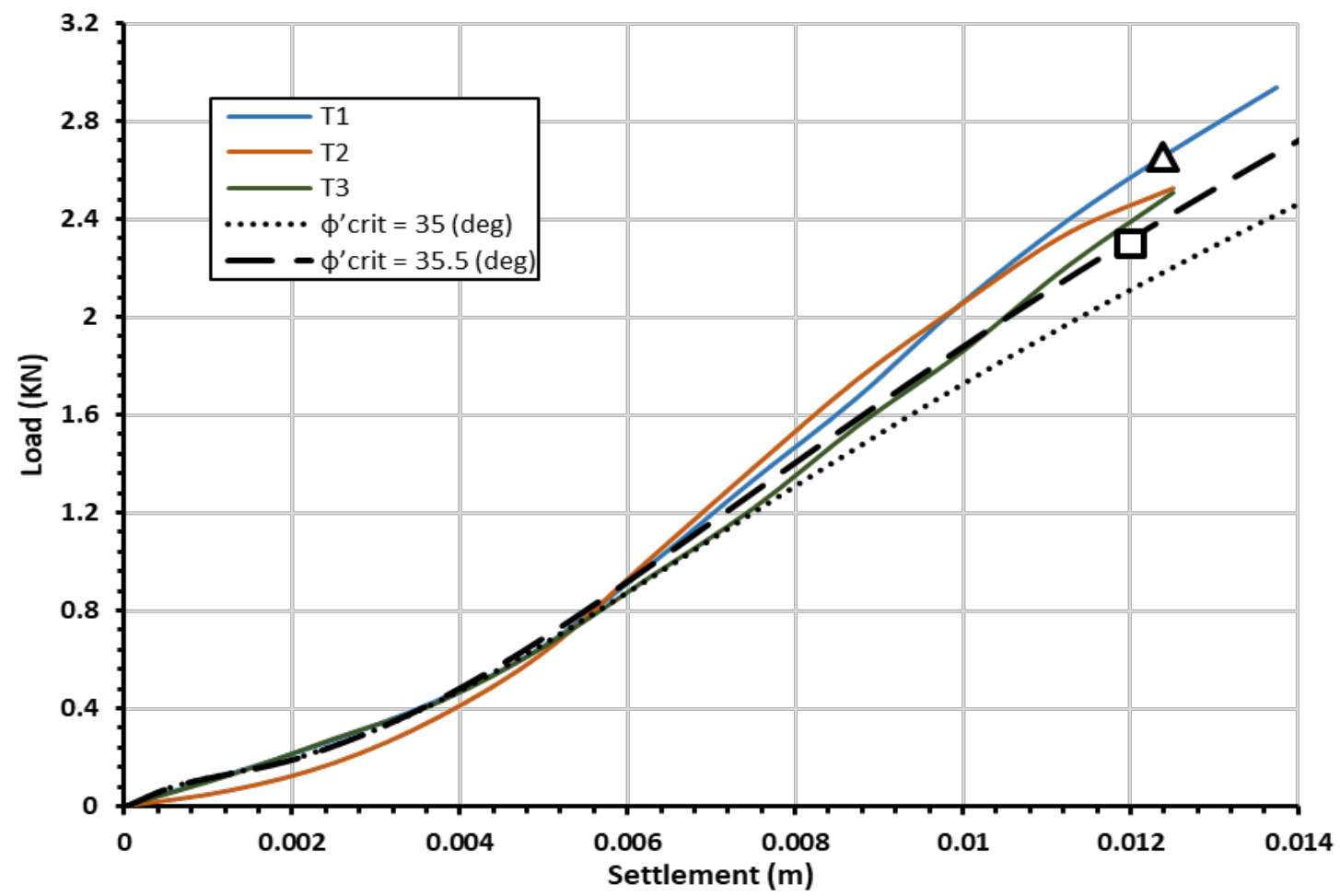

(b)

Fig. 8. Comparison of the calculated and experimental load-settlement profiles for (a) 2D bearing plate and (b) 3D bearing plate 


\section{Theoretical Problem}

This section looks at a hypothetical problem designed to investigate the influence of attaching a bearing plate to a pile. A close-ended steel pile with $0.3 \mathrm{~m}$ diameter is assumed to be driven in a uniform sand deposit with properties identical to the sand used in this experiment. At the surface, the sand deposit has an $I_{D}$ of 0.22 that increases with depth. The rate of increase of $I_{D}$ with depth is calculated by using Equation [2], where a $\kappa$ value of 0.058 was used. The effective stress, p' was calculated by taking an at-rest earth coefficient of 1 -sin $\phi$ ' crit.

Figure 9 shows the results of the hypothetical problem, where the capacity of the pile alone is compared to that of the same pile with a $2 \mathrm{D}(0.6 \mathrm{~m})$ and a 3D $(0.9 \mathrm{~m})$ bearing plate attached. The capacity of the pile was calculated by the method suggested by Fleming et al. (2009), where they take dilatancy into account. The capacities of the bearing plate were calculated by using the method described in this paper. The results demonstrate the advantages of bearing plates.

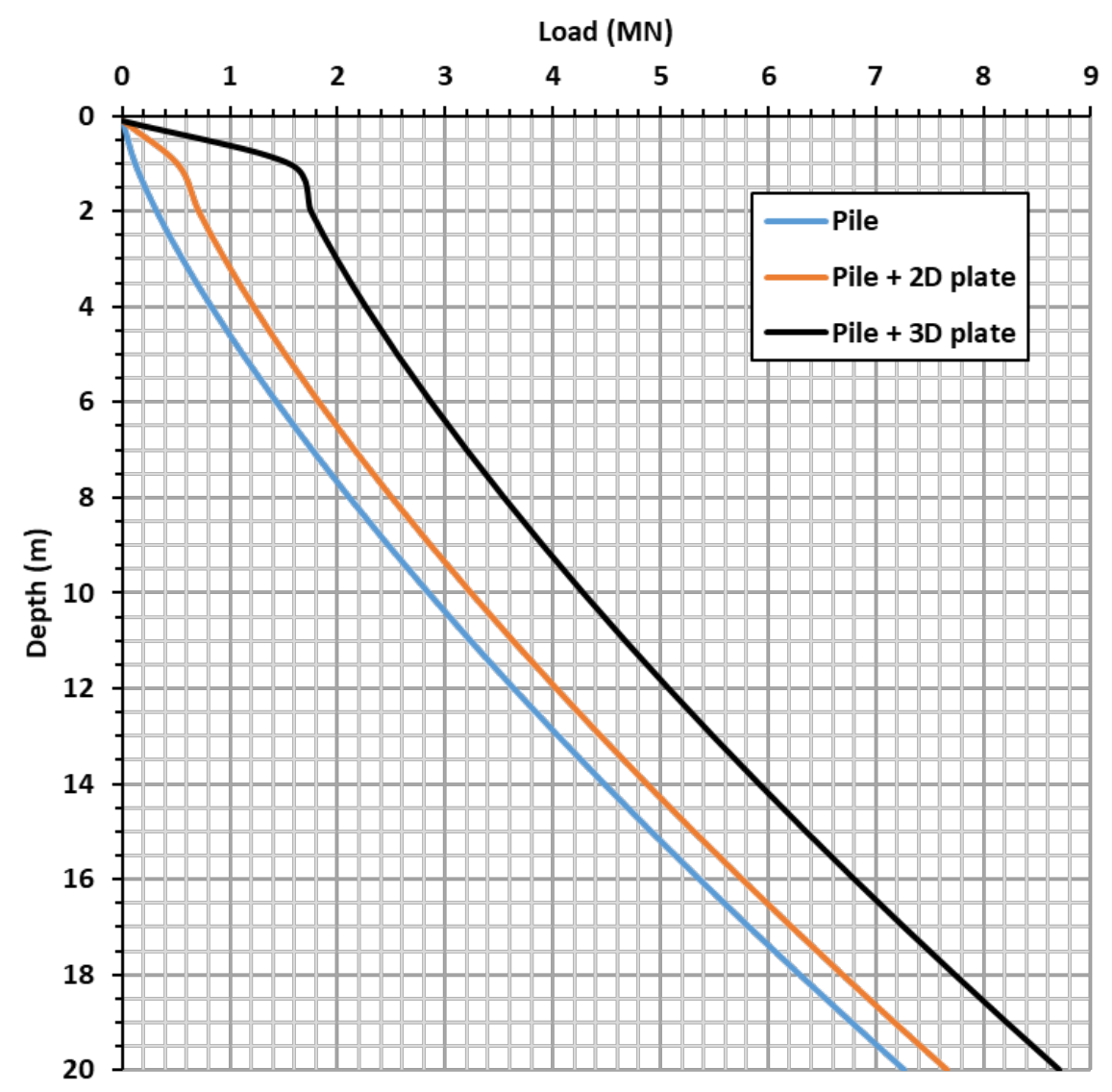

Figure 9. Results of the described hypothetical problem 
As per equation [6], settlements of $0.09 \mathrm{~m}$ and $0.16 \mathrm{~m}$ would be required to mobilise the capacities of the 2D and 3D plates used in Fig. 9. It is worth noting that with an increased stress, the rate of increase in settlement is lower. This is due to the logarithmic nature of the compression curve. This shows that as a footing gets larger, the rate of increase in compaction is smaller. This ultimately leads to a lower degree of dilation as p' would be greater but $I_{D}$ will remain relatively constant.

As per Fig.9, if the pile is required to carry a load of $2 \mathrm{MN}$, then it needs to be driven to a depth of $7.8 \mathrm{~m}$. However, if the 2D plate is attached, the driving depth would reduce to $6.5 \mathrm{~m}$. Alternatively, if the 3D plate is attached, then the pile needs to be driven to a depth $3 \mathrm{~m}$ only. This shows that attaching either the 2D or the 3D plate can save $0.94 \mathrm{~m}^{2}$ and $3.78 \mathrm{~m}^{2}$ of steel. However, if the pile is required to support a load of $6 \mathrm{MN}$, then the saving in steel reduces to $0.56 \mathrm{~m}^{2}$ for the 2D plate and $2.28 \mathrm{~m}^{2}$ for the $3 \mathrm{D}$ plate. The reason behind that is that $\mathrm{I}_{\mathrm{D}}$ increases with depth. Additionally, at higher loads, small savings in steel may not be as attractive.

It is worth noting that these calculations are for close-ended driven piles, for other types of piles, Fleming et al. (2009) advises reducing the calculated capacities to 30 to 50\% of end-bearing for bored piles and $80 \%$ of end-bearing for open-ended piles. Moreover, friction fatigue was not considered here, where it would be reduced with decreasing driving depths. By taking these factors into account, bearing plates could be more beneficial for different type of piles and different considerations.

\section{Summary and Conclusion}

Three test programmes of 1-g small-scale displacement tests were conducted to investigate the effect of attaching plates of variable sizes to model pipes driven in dry, loosely packed, uniform Leighton Buzzard sand. The results show average increases in capacity of $0.5 \mathrm{kN}$ for the 2D plate (20\%) and $2.67 \mathrm{kN}(110 \%)$ for the 3D plate, when compared to the average increase in capacity with depth for the same model pipe. The conducted back-analysis showed reasonable results that agreed with the general premise of the paper where the relative density increased for the larger plates which results in increasing the degree of dilation. An expression was derived that was used to back-calculate the critical frictional angle of the sand, which agreed well with values in 
literature. A hypothetical scenario was outlined that showed a potential to reduce the overall depth of piles by using the plate.

The new pile design shows a potential to ensure a more efficient use of resources to reduce costs and carbon footprint associated with the manufacturing, handling and disposal of materials, despite the limitation of using thicker material for the plate in order to achieve rigidity and the additional preparatory work needed for installation. Ultimately, the exact nature of the benefit of attaching a bearing plate to a pile would be project- specific. For example, a soil stratum of strong-over-weak layer would make the use of a bearing plate even more advantageous. On looser sandy deposits (as of the soil prepared in this experiment); the bearing plate tends to compact the surface soil to a higher density resulting in a greater capacity. Alternatively, a bearing plate can be used to add a factor of safety in circumstances where the magnitude of load is not yet determined (e.g. design build tenders, where the substructure is built before the superstructure is designed).

By examining the test results in Figures 8a and to a greater extent 8b, the slope of the load/displacement curves increases as load increases. It is believed that this is due to the rearrangement of the sand particles to a denser state near the vicinity of the plate. This was also visually noticed during the experiments. This may show that there is an increase in both total resistance but more importantly a decrease in deflection at the same loads which is very important at a service level displacement.

The exact construction method can differ; instead of welding the plate, a key-lock mechanism can be used to join the plate and the pile. This can allow the plate to be jacked in the soil before it gets connected to the pile; to ensure a stiff response upon loading. Alternatively, in more flexible structures where settlement is allowed, the plate could be designed to add a factor of safety against shear failure. This shows the flexibility of incorporating such design into the construction industry although it may be challenging due to the current practice of cutting or splicing the piles in order to attain the required capacity where the depth of embedment of is variable due to the uncertainty in subsurface conditions.

In terms of application of the results from this study to practical problems, it should be noted that the current study is largely a 'proof of concept' and the practical contribution of the results will 
have to be verified with testing and monitoring. Centrifuge or full-scale testing are necessary to validate the use of bearing plates and further explore any scale effect. Although dilation has been considered, the stress levels in the conducted experiments are significantly smaller than the ones encountered on site. Similarly, future tests and monitoring should look into the group effects and the measurements obtained from strain gauges instrumented piles on the side resistance shadowing from the plate bearing pressures; the determination of any influence of the stress bulb on group axial/lateral resistance and possible scale effects would also need to be investigated Additionally, further studies are required to determine the optimal construction technology of the bearing plate and whether post-installation jacking is possible. 


\section{References}

Al-Aghbari, M.Y. And Mohamedzein, T.E.A., 2004. Model testing of strip footings with structural skirts. Ground Improvement. Vol. 7, No. 1, 1-7

Been, K., Jefferiest, M.G. And Hachey, J. 1991. The critical state of sands. Géotechnique, 41(3), 365-381.

Bolton, M.D. 1986. The Strength and Dilatancy of Sands. Géotechnique, Vol. 36, pp. 65-78.

Cavallaro, A., Maugeri M., and Mazzarella, R., 2001. Static and Dynamic Properties of Leighton Buzzard Sand from Laboratory Tests. $4^{\text {th }}$ International Conferences on Recent Advances in Geotechnical Earthquake Engineering and Soil Dynamics. Missouri, USA. Paper No. 113.

Deeks, A.D., White, D.J. and Bolton, M.D., 2005. A comparison of jacked, driven and bored piles in sand. In ICSMGE. T. Committee (Ed.), Proceedings of the 16th International Conference on Soil Mechanics and Geotechnical Engineering. Osaka, Japan ed., Vol. 4, pp. 2103-2106. Rotterdam, Netherlands: Millpress.

Fleming, W.K., Weltman, A.J., Randolph, M.F. and Elson, W.K. (1992). Piling engineering (3rd ed.). Milton Park, Abingdon, Oxon. Taylor \& Francis Group.

Golder, H.Q., Fellenius, W., Kogler, F., Meischeider, H., Krey, H. \& Prandtl, L. 1941. the ultimate bearing pressure of rectangular footings. Journal of the Institution of Civil Engineers, Vol.17, 161-174.

Head, K. (2006). Manual of soil laboratory testing Vol. 1, Soil classification and compaction tests (3rd ed.). Dunbeath, Scotland: Whittles Publishing. Pp. 316-318

Igoe, D.J., Gavin, K.G. and O’Kelly, B.C., 2011. Shaft capacity of open-ended piles in sand. Journal of Geotechnical and Geoenvironmental Engineering, Vol. 137, 903-913.

Kim, K.E. and Andrawes, B., 2017. Retrofitting of bridge abutment timber piles using fiberreinforced polymer composites. Journal of structural integrity and maintenance. Vol. 2, NO. 1, 29-38

Penna, A., Sorrentino, G., d’Onofrio, A., Silvestrie, F. and Simonelli, A.L., 2016. Dynamic behaviour of the Leighton Buzzard Sand-B under very low confining stresses. 1st IMEKO TC-4 International Workshop on Metrology for Geotechnics Benevento, Italy, March 1718. 200-203

Sun, Y., Xiao, Y. and Hanif, K. F., 2015. Compressibility dependence on grain size distribution and relative density in sands. Science China. Technological Sciences, 58 (3), 443-448 
Teh, K.L., 2007. Punch-Through of Spudcan Foundation in Sand Overlying Clay. PhD thesis. National University of Singapore.

White, D.J., Teh, K.L., Leung, C.F. and Chow, Y.K. 2008. A comparison of the bearing capacity of flat and conical circular foundations on sand. Geotechnique, 58, 781-792.

Whitlow, R., 2001. Basic soil mechanics (4th ed.). Essex, England. Pearson Education Limited.

Zhu, F.Y., Clark, J.I. and Phillips, R. 2001. Scale effect of strip and circular footings resting on dense sand. Journal of Geotechnical and Geoenvironmental Engineering, Vol. 127, 613621. 